\title{
Genomic and kinetic analysis of novel Nitrospinae enriched by cell sorting
}

\author{
Anna J. Mueller $\mathbb{1}^{1} \cdot$ Man-Young Jung ${ }^{1,2} \cdot$ Cameron R. Strachan $^{3,4} \cdot$ Craig W. Herbold $^{1} \cdot$ Rasmus H. Kirkegaard $\mathbb{I}^{5}$ • \\ Michael Wagner $\mathbb{D}^{1,5,6} \cdot$ Holger Daims $\mathbb{D}^{1,6}$
}

Received: 29 May 2020 / Revised: 23 September 2020 / Accepted: 5 October 2020 / Published online: 16 October 2020

(c) The Author(s) 2020. This article is published with open access

\begin{abstract}
Chemolithoautotrophic nitrite-oxidizing bacteria (NOB) are key players in global nitrogen and carbon cycling. Members of the phylum Nitrospinae are the most abundant, known NOB in the oceans. To date, only two closely affiliated Nitrospinae species have been isolated, which are only distantly related to the environmentally abundant uncultured Nitrospinae clades. Here, we applied live cell sorting, activity screening, and subcultivation on marine nitrite-oxidizing enrichments to obtain novel marine Nitrospinae. Two binary cultures were obtained, each containing one Nitrospinae strain and one alphaproteobacterial heterotroph. The Nitrospinae strains represent two new genera, and one strain is more closely related to environmentally abundant Nitrospinae than previously cultured NOB. With an apparent half-saturation constant of $8.7 \pm$ $2.5 \mu \mathrm{M}$, this strain has the highest affinity for nitrite among characterized marine NOB, while the other strain $(16.2 \pm 1.6 \mu \mathrm{M})$ and Nitrospina gracilis $(20.1 \pm 2.1 \mu \mathrm{M})$ displayed slightly lower nitrite affinities. The new strains and $N$. gracilis share core metabolic pathways for nitrite oxidation and $\mathrm{CO}_{2}$ fixation but differ remarkably in their genomic repertoires of terminal oxidases, use of organic $\mathrm{N}$ sources, alternative energy metabolisms, osmotic stress and phage defense. The new strains, tentatively named "Candidatus Nitrohelix vancouverensis" and "Candidatus Nitronauta litoralis", shed light on the niche differentiation and potential ecological roles of Nitrospinae.
\end{abstract}

Supplementary information The online version of this article (https:// doi.org/10.1038/s41396-020-00809-6) contains supplementary material, which is available to authorized users.

Holger Daims

holger.daims@univie.ac.at

1 University of Vienna, Division of Microbial Ecology, Centre for Microbiology and Environmental Systems Science, Althanstrasse 14, 1090 Vienna, Austria

2 Department of Science Education, Jeju National University, 102 Jejudaehak-ro, Jeju 63243, Republic of Korea

3 Department for Farm Animals and Public Health, Food Technology and Veterinary Public Health, University of Veterinary Medicine Vienna, Veterinärplatz 1, 1210 Vienna, Austria

4 FFoQSI GmbH, Technopark 1C, 3430 Tulln, Austria

5 Department of Chemistry and Bioscience, Center for Microbial Communities, Aalborg University, Fredrik Bajers Vej 7H, 9220 Aalborg, Denmark

6 University of Vienna, The Comammox Research Platform, Vienna, Austria

\section{Introduction}

Bioavailable nitrogen is essential to all life on earth and the growth limiting factor in many ecosystems. With that said, in marine habitats, an excess in nitrogen availability due to anthropogenic pollution can cause dramatic effects such as coastal eutrophication and the formation of hypoxic dead zones [1]. The majority of fixed nitrogen in marine systems is composed of nitrate $\left(\mathrm{NO}_{3}{ }^{-}\right)$[2]. While microbially catalyzed nitrite oxidation by chemolithoautotrophs is thought to be the most significant biological pathway in terms of nitrate production, surprisingly little is known about the underlying microbiology in the oceans. The known diversity of marine nitrite-oxidizing bacteria (NOB) consists of members of the phylum Nitrospinae and representatives of the genera Nitrospira, Nitrococcus, Nitrobacter, and Nitrotoga [3]. Among these, the Nitrospinae (recently proposed to be renamed to Nitrospinota [4]) are the most abundant NOB in the majority of the marine environments studied so far. They have been found to be present in a wide range of habitats including the free water column, oxygen minimum zones (OMZs), sediments, and deep-sea trenches 
[5-17]. Interestingly, nitrite oxidoreductase (NXR), the key enzyme for nitrite oxidation, was found to be highly abundant in metaproteomic studies of OMZs [11, 12] and high in situ nitrite oxidation rates were measured, although nitrite oxidation is considered to be an aerobic process and OMZs are strongly oxygen limited [5, 18, 19]. In addition to their importance in the nitrogen cycle, the Nitrospinae have been suggested to play a major role in dark ocean carbon fixation by contributing up to $15-45 \%$ of the fixed inorganic carbon in some environments [20]. The contribution of Nitrospinae to $\mathrm{CO}_{2}$ fixation is, however, still under debate $[21,22]$, partially due to a lack of cultured representative organisms.

To date, only two strains from the Nitrospinae have been isolated, both of which are members of the genus Nitrospina (N. gracilis and N. watsonii) and are closely related to each other (97.9\% $16 \mathrm{~S}$ rRNA identity) [23, 24]. Experimental and genomic evidence obtained thus far from these two cultured strains point to Nitrospina spp. being chemolithoautotrophic NOB and obligate aerobes [23-25]. However, single-cell genomic analyses of marine bacteria have revealed a much higher diversity of Nitrospinae. Accordingly, the phylum contains at least two additional major phylogenetic lineages, which are only distantly affiliated with the genus Nitrospina and are referred to as "Clade 1" ("Candidatus $(\mathrm{Ca}$.) Nitromaritima") and "Clade 2" [6, 20]. Intriguingly, these uncultured organisms are considerably more abundant in the environment than Nitrospina spp. [20]. They were predicted to be NOB based on the presence of $n x r$ genes, but direct physiological evidence for this activity has been lacking. Various other NOB, such as Nitrospira members, have been shown to be able to utilize alternative energy metabolisms, including the oxidation of hydrogen or formate coupled to oxygen or nitrate reduction [26-28]. There is also some genomic and metagenomic evidence for putative alternative metabolisms in the Nitrospinae, such as hydrogen oxidation, sulfite oxidation, and nitrate reduction, which remain to be tested [6, 7, 20, 25]. Indeed, ecophysiological analyses of Nitrospinae outside the described genus Nitrospina are hampered by the lack of any cultivated strains that could systematically be characterized. The major cause of this deficiency is the recalcitrance of most NOB to cultivation and the time needed to isolate these organisms by traditional approaches [24, 29], which can take more than a decade.

We therefore employed an accelerated approach based on live cell sorting and obtained two binary co-cultures, each containing a novel Nitrospinae genus and a heterotrophic bacterium. Excitingly, one of the strains groups with the environmentally abundant but uncultured Nitrospinae clades 1 and 2 [20]. Here, we describe both strains, including genomic characterization and determination of their nitrite affinities, in order to expand our understanding of the diversity and ecophysiology of the Nitrospinae and provide new model organisms from this globally important phylum.

\section{Materials and methods}

\section{Sample collection, pre-enrichment and cultivation of NOB}

Sandy coastal surface sediment $(0-3 \mathrm{~cm})$ samples were taken at Burrard Inlet, Vancouver, Canada $\left(49^{\circ} 16^{\prime} 22.1^{\prime \prime} \mathrm{N}\right.$ $123^{\circ} 11^{\prime} 32.5^{\prime \prime} \mathrm{W}$ ) in November 2016 and in Elba, Italy $\left(42^{\circ} 43^{\prime} 48.1^{\prime \prime N} 10^{\circ} 09^{\prime} 23.2^{\prime \prime} \mathrm{E}\right)$ in November 2016. Aliquots of the sediments were inoculated into $50 \mathrm{ml}$ Schott glass bottles filled with $25 \mathrm{ml}$ marine minimal medium at $\mathrm{pH}$ 7.4-7.6 containing $4.2 \mu 1 \mathrm{l}^{-1}$ supplement solution $\left(0.02 \mathrm{~g} \mathrm{l}^{-1}\right.$ biotin, $0.02 \mathrm{~g}^{-1}$ folic acid, $0.10 \mathrm{~g} \mathrm{l}^{-1}$ pyridoxine $\mathrm{HCL}$, $0.05 \mathrm{gl}^{-1}$ riboflavin, $0.05 \mathrm{gl}^{-1}$ nicotinic acid, $0.05 \mathrm{gl}^{-1}$ DL-pantothenic acid, $0.05 \mathrm{gl}^{-1}$ P-aminobenzoic acid, $2.00 \mathrm{~g}^{-1}$ choline chloride and $0.01 \mathrm{~g} \mathrm{l}^{-1}$ vitamin $\mathrm{B}_{12}$ ) and $0.5 \mathrm{mM} \mathrm{NO}_{2}{ }^{-}$, and incubated at $28^{\circ} \mathrm{C}$ in the dark without agitation [30]. The marine minimal medium was modified from the medium used for the cultivation of $N$. gracilis and $N$. watsonii by replacing natural seawater with $33.4 \mathrm{~g} \mathrm{l}^{-1}$ (Vancouver) and $39.9 \mathrm{gl}^{-1}$ (Elba) red sea salts (Red Sea Aquaristic) dissolved in Milli-Q water [23-25]. A higher salinity was chosen for the Elba enrichment to reflect the higher salt concentrations in the Mediterranean Sea. The enrichments were regularly checked for nitrite consumption and nitrate formation by using nitrite/nitrate test stripes (Merckoquant, Merck). Upon consumption of nitrite, the cultures were replenished with $0.5-1 \mathrm{mM}$ nitrite (Vancouver Nitrospinae) or up to $5 \mathrm{mM}$ nitrite (Elba Nitrospinae and $N$. gracilis) (final concentrations). Once nitrite oxidation was consistently observed, aliquots of the cultures were transferred at a 1:10 ratio into fresh media. Unless stated otherwise, the Vancouver and Elba Nitrospinae were cultured as described above. $N$. gracilis was grown at the same red sea salt concentration as the Vancouver Nitrospinae. Growth of the Nitrospinae strains on solid media was tested on Marine Broth 2216 (Difco, BD) and the strain specific marine minimal media that were solidified with $15 \mathrm{gl}^{-1}$ agar.

\section{Cell sorting and activity screening}

Cells were concentrated from $10 \mathrm{ml}$ of the enrichment cultures by centrifugation $\left(4500 \times g, 20 \mathrm{~min}, 28^{\circ} \mathrm{C}\right)$ using a swing-bucket rotor (Eppendorf) and resuspended in $200 \mu \mathrm{l}$ of the supernatant. Subsequently, the cells were sorted into sterile 96-well tissue culture plates (VWR, item no. 10062900 ) by using the single cell sorting option at a pressure of 60 psi on a MoFlo Astrios Flow Cytometer (Beckman 
Coulter) equipped with a $70 \mu \mathrm{m}$ jet in air nozzle. On the instrument, cells were visualized in the forward and side scatter channel and small, non-cell particles were excluded; otherwise no gating was applied. The wells of the microtiter plates contained $200 \mu \mathrm{l}$ of sterile mineral salt medium amended with supplements (see cultivation details above) and 0.25 $\mathrm{mM}$ sodium nitrite. For the cultivation of the Vancouver sourced Nitrospinae strain, the sorting medium additionally contained $0.1 \mathrm{mM}$ sodium pyruvate to alleviate oxidative stress [31]. The 96-well microtiter plates were placed in closed plastic bags to prevent evaporation, incubated at $28^{\circ} \mathrm{C}$ in the dark without agitation and $10 \mu \mathrm{l}$ aliquots of each well were regularly checked for nitrite consumption with the Griess assay [32]. Selected wells, which showed nitrite consumption, were gradually scaled up by transferring the cultures into larger volume microtiter plates and doubling the culture volume after each round of nitrite consumption up to $3.2 \mathrm{ml}$ and then to a final volume of 25 or $50 \mathrm{ml}$ in Schott bottles. The cultures were further cultivated as described for the enrichments (see above). Once sufficient biomass was available, the enriched nitrite-oxidizing organisms were provisionally identified by full-length $16 \mathrm{~S}$ rRNA gene amplification and Sanger sequencing.

The morphology of the cells was visualized via scanning electron microscopy (SEM) and catalyzed reporter deposition fluorescence in situ hybridization (CARD-FISH) with the Nitrospinae specific 16 S rRNA-targeted probe Ntspn759 [21] (Supplemental Materials and Methods).

\section{Genomic and phylogenetic analyses}

DNA was extracted from the cultures and complete genomes were obtained through Illumina and Nanopore sequence coassemblies. A 16S rRNA gene phylogenetic tree was calculated, and the genomes were annotated on the MicroScope platform (MAGE Workflow version: 1.8 [33] (Supplemental Materials and Methods).

Publicly available Nitrospinae genomes, including metagenome assembled genomes (MAGs) and single-cell amplified genomes (SAGs), were retrieved from NCBI and from the JGI genome portal (see Table $\mathrm{S} 1$ for details). Completeness and contamination of the genomes was assessed by CheckM (v. 1.0.18) (Table S1), and phylogenetic analyses were conducted on genomes that were more than $80 \%$ complete and $<10 \%$ contaminated [34]. A phylogenetic tree was calculated with an alignment of concatenated conserved bacterial marker proteins, made with the GTDB (Genome Taxonomy Database) toolkit (v. 0.3.2), using IQ-TREE (v. 1.6.11, model: $\mathrm{LG}+\mathrm{F}+\mathrm{R} 5$ as chosen by automatic model selection and 1000 ultrafast bootstrap runs) [4, 35-37]. The genomes of Nitrospira moscoviensis, G. metallireducens, and D. multivorans served as the outgroup. Clades within the Nitrospinae were depicted as they have been previously described in the literature $[6,20]$. Average amino acid identity (AAI) and whole-genome nucleotide identity (gANI) were calculated as described elsewhere [38-40] and visualized using $\mathrm{R}$ (v. 3.6.1) with the R package tidyverse (v. 1.3.0) [41]. The GTDB-TK output (Table S1) was used to delineate phylogenetic affiliations beyond the genus level [4].

The raw reads and genomes of the novel Nitrospinae strains were submitted to NCBI under the Bioproject accession PRJNA602816 and the Biosamples SAMN13976148 ("Ca. Nitrohelix vancouverensis" VA) and SAMN13976151 (" $\mathrm{Ca}$. Nitronauta litoralis" EB). The genomes are further available on the MicroScope platform under the accession NTSPN23.2 ("Ca. Nitrohelix vancouverensis" VA) and NTSPN 3.2 (“Ca. Nitronauta litoralis” EB).

\section{Nitrite oxidation kinetics}

Nitrite oxidation kinetics of the Nitrospinae co-cultures and $N$. gracilis were quantified by measuring nitrite-dependent oxygen consumption in a microrespirometry (MR) system (Unisense) as described in detail by Kits et al. [42]. To concentrate the biomass for MR, cells were collected from 100 to $300 \mathrm{ml}$ of culture with Amicon Ultra-15 tubes (Millipore) by centrifugation $\left(4500 \times g, 10 \mathrm{~min}, 28^{\circ} \mathrm{C}\right)$ using a swing-bucket rotor (Eppendorf). Concentrated biomass was washed and resuspended in nitrite free growth medium for the MR experiments. The media did not contain supplements to prevent oxygen respiration due to the degradation of organic compounds by the co-enriched, heterotrophic bacteria during the MR experiment. Culture biomass was incubated in a water bath set to the experimental temperature prior to being transferred to a $2 \mathrm{ml}$ glass MR chamber with a stir bar. All MR experiments were performed with $300 \mathrm{rpm}$ stirring at $28^{\circ} \mathrm{C}$. Small culture volumes $(\sim 10 \mu \mathrm{l})$ were taken before and immediately after nitrite injection, and $\sim 5 \mathrm{~min}$ after nitrite depletion for nitrite/ nitrate measurements to confirm stoichiometric conversion of oxygen, nitrite and nitrate. Protein concentrations were determined with the Pierce BCA protein assay (ThermoScientific) and cell abundances by qPCR (Supplementary Methods, Table S2). All experiments were replicated three times or more, using at least two different cultures on different days (see Results and Discussion for total biological and technical replicates per strain). For one replicate of each strain, images of the cells stained with DAPI were taken before and after the MR measurements by using an epifluorescence microscope (Zeiss). These images were used to check whether the cells in the MR chamber had formed aggregates, which could cause oxygen diffusion limitations and thus affect the measured respiration rates and the inferred nitrite oxidation kinetics. No aggregates were observed. 


\section{Results and discussion}

\section{Cultivation of novel Nitrospinae representatives}

For the initial enrichment of marine NOB, nitrite-containing mineral media were inoculated with coastal surface sediment samples taken in Vancouver, Canada, and Elba, Italy. Within 4 weeks of incubation, nitrite oxidation to nitrate was detected in the cultures and this activity continued to be observed after subsequent replenishment of nitrite and transfers of culture aliquots into fresh medium. Usually, the further purification of NOB from accompanying organisms in the enrichment cultures is hindered by the very slow growth and inability of most NOB (including all cultured Nitrospinae) to grow on solid media. To expedite the purification of Nitrospinae strains from our initial enrichments, which was previously a laborious and lengthy process [24], we developed a method for the physical separation, activitybased identification of NOB, and subcultivation in 96-well microtiter plates. This method uses random, non-fluorescent, single-cell sorting using a fluorescence activated single cell sorting (FACS) instrument paired with a nitrite consumption activity screen (Fig. S1a). Thus, it differs from a previously reported FACS isolation approach for Nitrospira NOB from activated sludge, where the NOB were targeted based on their known cell cluster size and shape, which had been determined by Nitrospira-specific rRNAtargeted FISH analysis before FACS was performed [43]. Our method does not rely on prior knowledge of the identity and morphology of the NOB [43] but is solely based on the detection of nitrite oxidation after sorting. Still, it might allow for a flexible selection of the sorted cell morphologies by adjusting the gating parameters. While the previous method facilitated the isolation of already known NOB, the approach used in our study was designed for the discovery of novel nitrite oxidizers that grow under the given conditions. It may also be suitable for the isolation of other microorganisms that can be efficiently sorted (i.e., grow in suspension or that can be suspended by sonication or other methods) and that perform a specific metabolism of interest, which is detectable by a colorimetric, fluorimetric, or other high-throughput assay. Examples include previously performed, high-throughput enzyme discoveries and the isolation of microalgae [44-46]. After sorting cells from the initial Vancouver and Elba enrichment cultures into one 96-well plate each, several wells showed nitrite-oxidizing activity within 3-4 weeks. Cells from three active wells from the Elba enrichment and 4 for the Vancouver enrichment ( $>4$ were active) were progressively transferred into larger culture volumes. This procedure led to the separate enrichment of two different Nitrospinae, one from each of the initial enrichments, that were identified by $16 \mathrm{~S}$ rRNA gene sequencing (Fig. S1b): strain VA (Vancouver) and strain EB (Elba). Interestingly, despite attempted singlecell sorting and various dilution to extinction attempts, an axenic culture could not be established for either of the two obtained Nitrospinae strains. Rather, these cultures represent binary co-cultures each containing one Nitrospinae strain, one alphaproteobacterial strain, and no other detectable microorganisms. Overall, using this single-cell sorting and screening method, we were able to obtain the two binary co-cultures from the environmental samples in $\sim 10$ months.

\section{Co-enrichment with Alphaproteobacteria}

Pure cultures of the two co-enriched heterotrophic strains were obtained on Marine Broth Agar. Subsequent 16S rRNA gene analysis of these isolates showed that the two Nitrospinae strains had been co-cultured with members of two distinct genera within the Alphaproteobacteria. Strain VA was co-cultured with a bacterium most closely related to a Stappia stellulata strain (NR_113809.1, 99.58\% 16S rRNA gene sequence identity), whereas the EB strain culture contained a Maritimibacter alkaliphilus strain (NR_044015.1, 100\% $16 \mathrm{~S}$ rRNA gene sequence identity). Both these species have previously been isolated from marine environments and have been described as alkaliphilic chemoorganoheterotrophs that can use a wide variety of simple and complex organic substrates $[47,48]$. In our cultures, which were only provided with nitrite for growth, the alphaproteobacterial strains may have lived off simple organic compounds that were excreted by the autotrophic Nitrospinae. Since the NOB could not be grown separately from the heterotrophs, it is tempting to speculate that the Nitrospinae strains also benefitted, for example, from reactive oxygen species (ROS) protection by the heterotrophs. Superoxide dismutase and catalase genes are present in the genomes of both co-cultured alphaproteobacteria, and other isolates of both species are catalase positive $[47,48]$. Similar interactions have already been observed in marine autotroph-heterotroph co-cultures, including other nitrifiers [49-51].

\section{Phylogeny of the novel Nitrospinae}

Closed genomes were reconstructed for both Nitrospinae strains by co-assembling Illumina and Nanopore sequencing data. Since the genome of $N$. gracilis was nearly completely sequenced but not closed [25] (Table S3), the obtained genomes represent the first closed genomes from Nitrospinae. With a length of $>3.9 \mathrm{Mbp}$, Nitrospinae strain EB has a larger genome than the other cultured Nitrospinae strains sequenced to date (Table S3).

Phylogenetic analysis of the 16S rRNA genes (Fig. S1b) showed that the Nitrospinae strains VA and EB are only distantly related to $N$. gracilis $(93 \%$ sequence identity with 


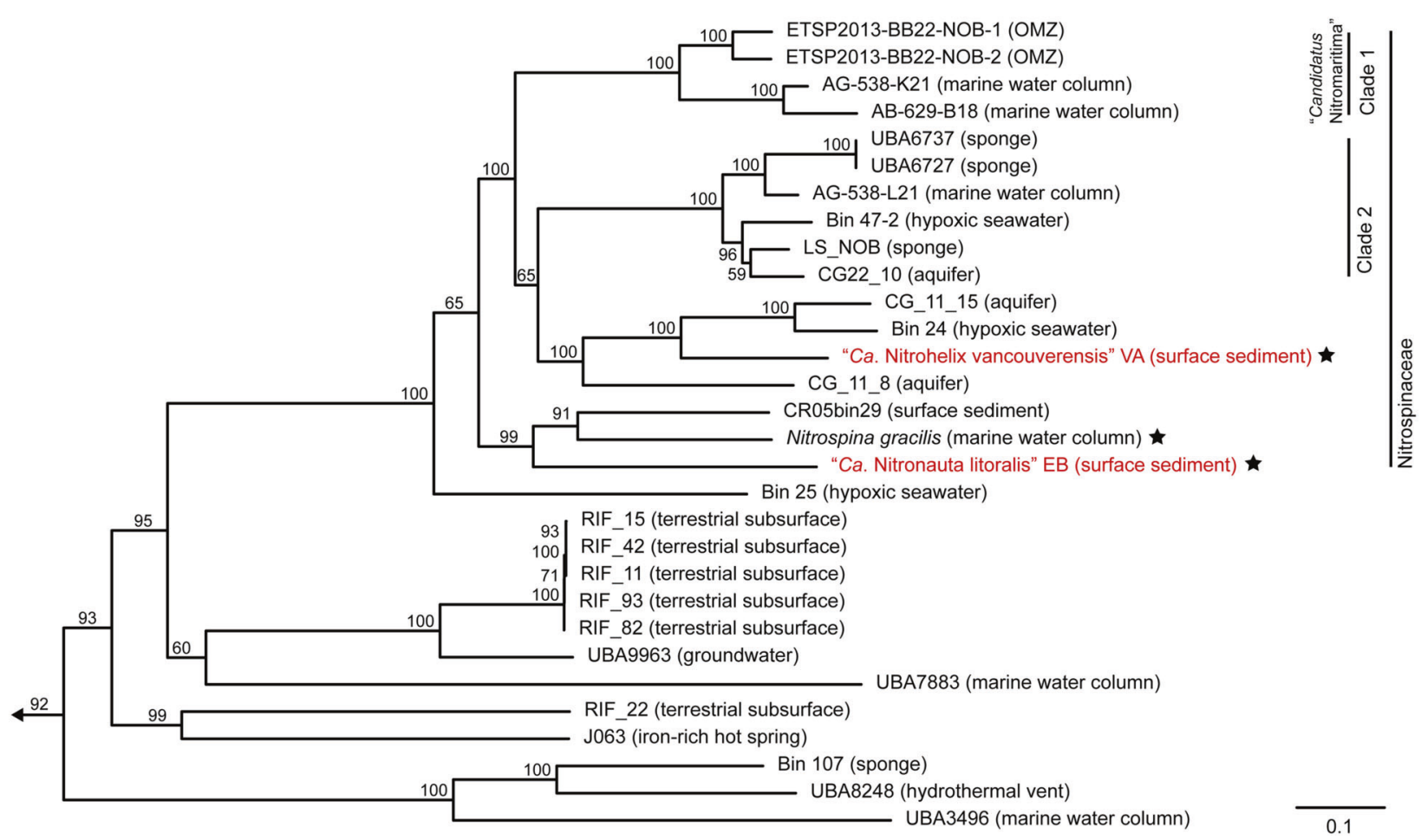

Fig. 1 Concatenated marker gene tree of the Nitrospinae. The maximum likelihood tree shows the phylogenetic positions of the two newly cultured strains (highlighted in red) within the phylum Nitrospinae. The tree was calculated from a concatenated alignment of 120 conserved bacterial marker proteins. Details of the Nitrospinae genomes, which were used to calculate this tree, are listed in Table S1. Numbers at branches indicate ultrafast bootstrap $(n=1000)$ support.

EB and $91 \%$ with VA), N. watsonii (92\% sequence identity with EB and $90 \%$ with VA), and to each other (90\% sequence identity). Since public databases contained only few $16 \mathrm{~S}$ rRNA gene sequences closely related to strains VA and EB (Fig. S1b), these strains seem to represent a yet underexplored diversity of Nitrospinae. A phylogenetic tree using conserved concatenated marker proteins from all available Nitrospinae genomes that are $>80 \%$ complete and $<10 \%$ contaminated, including MAGs and SAGs, further confirmed that the strains obtained here represent novel lineages (Fig. 1). In particular, strain VA was more closely related with the Clade 1 and 2 Nitrospinae than $N$. gracilis, although it was clearly not a member of either group. In the concatenated marker tree, it belonged to a third wellresolved clade with additional MAGs. The exact branching order between Clade 1,2, and this third clade remained unresolved (Figs. 1, S1b).

The novelty of the two cultured Nitrospinae strains was corroborated by genome average nucleotide identity (gANI) (Fig. S2) and average AAI (Fig. 2) analyses. Since strain VA, strain EB, and most of the Nitrospinae members in the dataset are quite distantly related (below the $96.5 \%$ species level cut-off [39]), gANI (Fig. S2) was not suitable to
Nitrospira moscoviensis, Desulfococcus multivorans, and Geobacter metallireducens were used as an outgroup. Cultured organisms are marked with an asterisk. Clades of the Nitrospinae are indicated as proposed elsewhere [6] and the family Nitrospinaceae is indicated as determined by GTDB-TK. The scale bar indicates 0.1 estimated substitutions per residue. The sample source is indicated in parentheses.

further resolve their taxonomic grouping. However, AAI analysis revealed a high genus-level diversity within the Nitrospinae, comprising 15 distinct genera according to a proposed $60 \%$ genus level cut-off [52]. Both strains from this study, VA and EB, represent a new genus with 55 and $58 \%$ AAI to $N$. gracilis, respectively, and 53\% AAI to each other (Fig. 2). The AAI analysis also suggested that each of the environmental clades 1 ("Ca. Nitromaritima") and 2 represent separate genera, with the lowest AAI values within each clade being $>70 \%$, and that these genera are distinct from the genus containing strain VA (Fig. 2). In order to make taxonomic inferences beyond the genus level, the GTDB-TK tool [38] was applied to the Nitrospinae genome dataset. GTDB-TK confirmed that strains VA and EB belonged to the Nitrospinaceae family but, in agreement with the AAI analysis, did not assign them to a genus (Tab. S2). While we showed that nitrite oxidation is spread among phylogenetically distant members within the Nitrospinaceae, no nitrite oxidation phenotype has been observed yet for the Nitrospinae members that do not belong to the Nitrospinaceae family.

Taken together, the phylogenetic, ANI, AAI, and GTDBTK analyses revealed a high genus-level diversity within the 


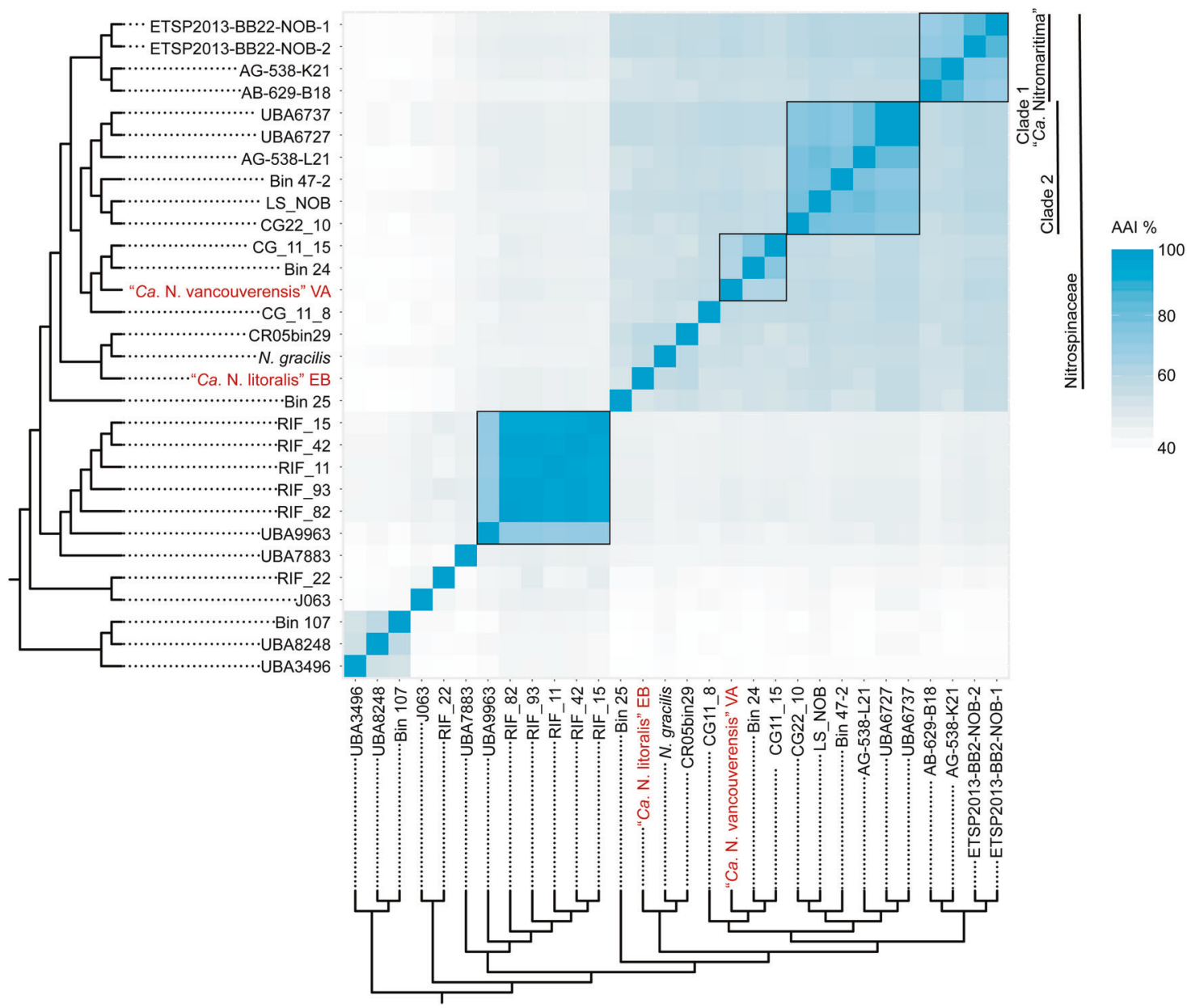

Fig. 2 Average amino acid identity (AAI) analysis of the Nitrospinae. Pairwise AAI values were calculated for the same set of Nitrospinae genomes that was used to reconstruct the phylogenetic tree in Fig. 1. The same tree is used here to annotate the heatmap. The two

Nitrospinae, the vast majority remaining uncultured and poorly characterized. Among all cultured Nitrospinae members, strain VA is most closely related with the uncultured but environmentally abundant clades 1 and 2 $[6,7,20,21]$.

\section{Cell morphology}

The morphologies of the new Nitrospinae strains were visualized using SEM, and by $16 \mathrm{~S}$ rRNA-targeted CARDFISH using a Nitrospinae-specific oligonucleotide probe (Ntspn759) [21]. Strain VA cells were helically shaped rods (Fig. 3a, d, g), whereas strain EB appeared to be short, slightly curved rods (Fig. 3b, e, h). Interestingly, neither of the two strains displayed the long, slender, rod-shaped morphology that was mostly observed for the previously isolated Nitrospina species, $N$. gracilis (Fig. 3c, f, i) [23]. The shape of strain VA (Fig. 3a, d, g) rather resembled Nitrospira species [53]. The short, slightly curved rod morphology of strain EB newly cultured strains are highlighted in red. Clades of the Nitrospinae are indicated as proposed elsewhere [6]. The boxes indicate the genus boundary at $60 \%$ identity.

(Fig. 3b, e, h) resembled the compact cell shape reported for aging cultures of $N$. watsonii [24] and environmental Nitrospinae [5]. While the helical shape of strain VA could be clearly distinguished from the co-cultured Stappia sp. using Nitrospinae-specific FISH (Fig. 3g) and SEM of the Stappialike isolate (Fig. S3a), assigning a morphology to strain EB was slightly more difficult due a more similar morphotype of the co-cultured Maritimibacter-like bacterium (Figs. 3e and S3b). According to SEM, the isolated Maritimibacter had a coccoid morphology (Fig. S3b) similar to the slightly smaller coccoid cells that were observed in the active co-culture with strain EB (Fig. 3e). Therefore, we assume that the slightly larger, curved rods in the SEM pictures (Fig. 3b, e) were Nitrospinae strain EB cells. However, the previously described morphological variability suggests that the cell shape of Nitrospinae is influenced by the growth stage and environment $[23,24]$. Thus, morphology would be of limited use as the sole criterion to differentiate Nitrospinae strains from each other and from other organisms. We propose the name 


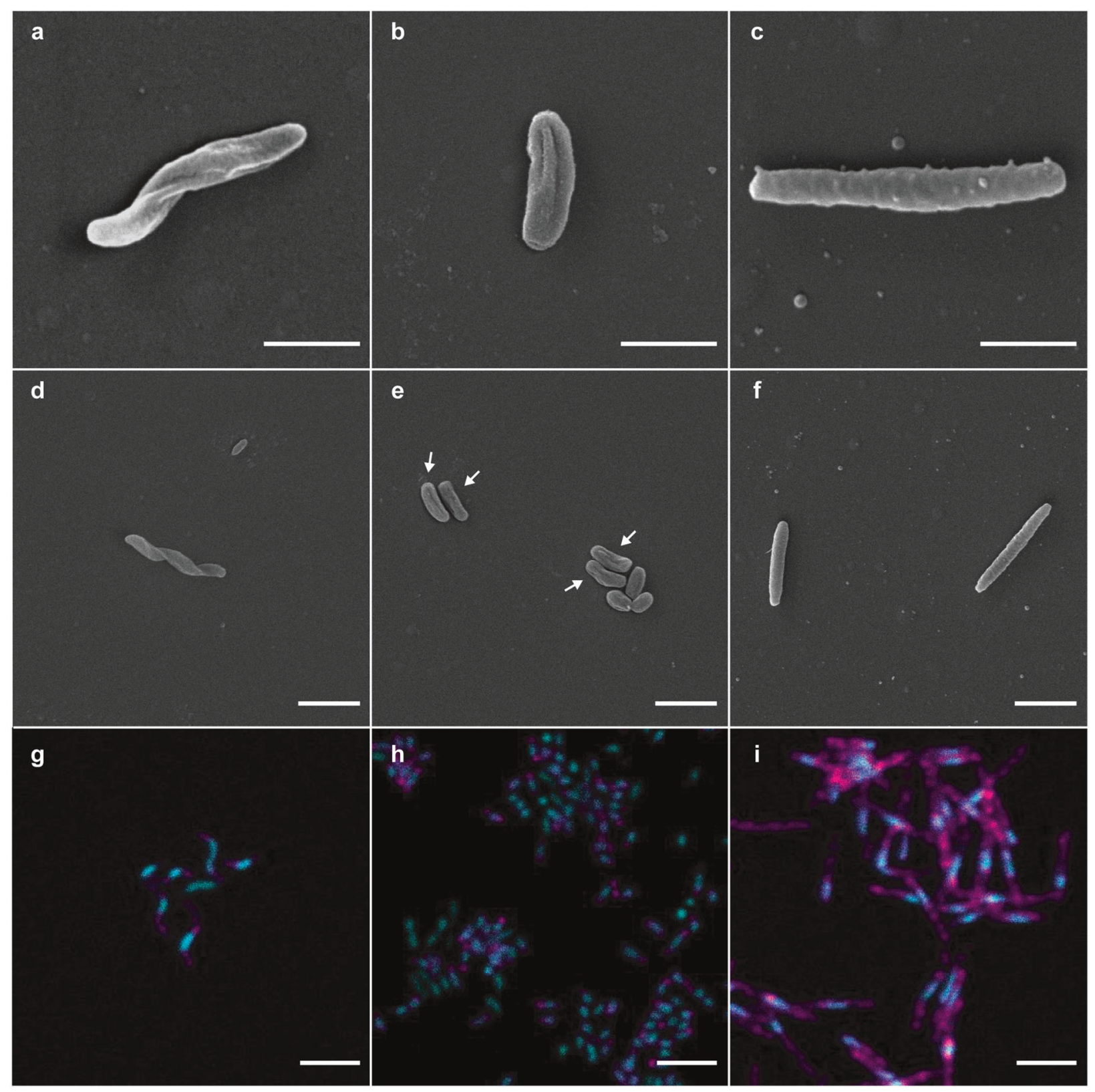

Fig. 3 Scanning electron microscopy (SEM) and CARD-FISH images of the two newly cultured Nitrospinae strains and $\mathrm{N}$. gracilis. a, d, $\mathbf{g}$ " $C a$. Nitrohelix vancouverensis" strain VA. b, e, h " $C a$. Nitronauta litoralis" strain EB. c, $\mathbf{f}, \mathbf{i} N$. gracilis. The short rod in (d) is a cell of the accompanying heterotroph Stappia sp. in the enrichment. e Shows slightly longer and slightly curved rods (strain EB, arrows) and

"Candidatus Nitrohelix vancouverensis" VA for strain VA based on its observed morphology and isolation source, and "Candidatus Nitronauta litoralis" EB for strain EB based on its isolation source.

\section{Nitrite oxidation: activity and kinetics}

Both Nitrospinae strains oxidized nitrite stoichiometrically to nitrate (Fig. S4). Exponential growth of " $\mathrm{Ca}$. N. shorter rods, which are cells of the accompanying heterotroph $M$. alkaliphilus in the enrichment. The scale bars in (a-c) depict $1 \mu \mathrm{m}$; all other scale bars depict $2 \mu \mathrm{m}$. g-i The $16 \mathrm{~S}$ rRNA-targeted probe Ntspn759 was used to detect Nitrospinae cells (magenta), and total nucleic acids were stained with SYBR Green (cyan).

vancouverensis" correlated with the consumption of nitrite (Fig. S4a), whereas "Ca. N. litoralis" did not enter the exponential growth phase during the incubation period (Fig. S4b). During the experiment, the relative abundance of "Ca. N. vancouverensis" compared to the co-cultured Stappia sp. increased pronouncedly from 6 to $75 \%$ (Fig. S4a). The relative abundance of " $\mathrm{Ca}$. N. litoralis" compared to the Maritimibacter sp. could not be reliably determined during the incubation experiment (Fig. S4b), but 
measurements taken after the MR experiments (see below) showed that the relative abundance of " $\mathrm{Ca}$. N. litoralis" ranged from $\sim 56$ to $99 \%$. Thus, the quantitative composition of each co-culture appeared to fluctuate and likely depended strongly on the availability of nitrite as the substrate for the NOB strains.

The kinetics of nitrite oxidation of $N$. gracilis and the two novel Nitrospinae strains were assessed by measuring the nitrite-dependent oxygen consumption in MR experiments. For all three NOB, nitrite oxidation followed Michaelis-Menten kinetics (Fig. S5). The stoichiometry of $\mathrm{NO}_{2}{ }^{-}$and $\mathrm{O}_{2}$ consumption was always close to $1: 0.5$ (N. gracilis: mean $=1: 0.49 ;$ s.d. $=0.02 ; n=8 ; " C a$. N. vancouverensis": mean $=1: 0.51$; s.d. $=0.01 ; n=4$; "Ca. N. litoralis": mean $=1: 0.51 ;$ s.d. $=0.02 ; n=5$ ). This ratio was expected for NOB [54] and indicates that $\mathrm{O}_{2}$ consumption by the co-enriched heterotrophs was only minor during the relatively short MR experiments (maximum $1 \mathrm{~h}$ ) and did not affect the kinetic analysis of " $\mathrm{Ca}$. N. vancouverensis" and " $\mathrm{Ca}$. N. litoralis". The apparent halfsaturation constant, $K_{\mathrm{m}(\mathrm{app})}$, of $N$. gracilis was determined to be $20.1 \mu \mathrm{M} \mathrm{NO}_{2}{ }^{-}$(s.d. $=2.1, n=8$ ) and the maximum reaction rate, $\mathrm{V}_{\text {max }}$, to be $41.4 \mu \mathrm{mol} \mathrm{NO}{ }_{2}^{-} \mathrm{mg}_{\text {protein }}{ }^{-1} \mathrm{~h}^{-1}$ (s.d. $=9.4, n=6$ ), which is highly similar to the previously reported $K_{\mathrm{m}(\mathrm{app})}$ and $\mathrm{V}_{\max }$ of the closely related $N$. watsonii $\left(18.7 \pm 2.1 \mu \mathrm{M} \mathrm{NO}{ }^{-}\right.$and $36.8 \mu \mathrm{mol} \mathrm{NO}{ }^{-} \mathrm{mg}^{-}$protein $^{-1} \mathrm{~h}$ ${ }^{-1}$ ) [55]. The $K_{\mathrm{m}(\mathrm{app})}$ measured for " $\mathrm{Ca}$. N. litoralis" was $16.2 \mu \mathrm{M} \mathrm{NO}{ }_{2}^{-}$(s.d. $=1.6, n=7$ ) and thus resembled the values of $N$. gracilis and $N$. watsonii. In contrast, with a $K_{\mathrm{m} \text { (app) }}$ of $8.7 \mu \mathrm{M} \mathrm{NO}_{2}{ }^{-}$(s.d. $=2.5, n=3$ ), “Ca. N. vancouverensis" showed a higher affinity for nitrite that was comparable with non-marine Nitrospira members $\left(K_{\mathrm{m}(\mathrm{app})}=6-9 \mu \mathrm{M} \mathrm{NO}_{2}^{-}\right)$, which have been the cultured NOB with the highest nitrite affinity known so far [54, 56]. Indeed, strain VA turned out to have the lowest $K_{\mathrm{m} \text { (app) }}$ of all hitherto analyzed marine NOB in culture (Fig. 4). Interestingly, among all cultured marine NOB, " $C a$. N. vancouverensis" is also most closely related to the Nitrospinae clades 1 and 2 that are abundant in oligotrophic waters [20] (see above). However, its $K_{\mathrm{m}(\text { app) }}$ is still $1-2$ orders of magnitude higher than the $K_{\mathrm{m}(\mathrm{app})}$ values of nitrite oxidation reported for environmental samples from an OMZ $\left(0.254 \pm 0.161 \mu \mathrm{M} \mathrm{NO}_{2}{ }^{-}\right)$and South China Sea waters $(0.03-0.5 \mu \mathrm{M})[22,57]$. The very high nitrite affinity observed with these samples might be explained by the presence of uncharacterized nitrite oxidizers, whose nitrite affinity exceeds that of all cultured NOB. However, it remains to be tested whether known NOB can persist under extremely low in situ nitrite concentrations. For example, the half-saturation constant for ammonia oxidizing bacteria spans several orders of magnitude under different growth temperatures [58]. Strongly different substrate affinities have also been observed for Nitrobacter winogradskyi

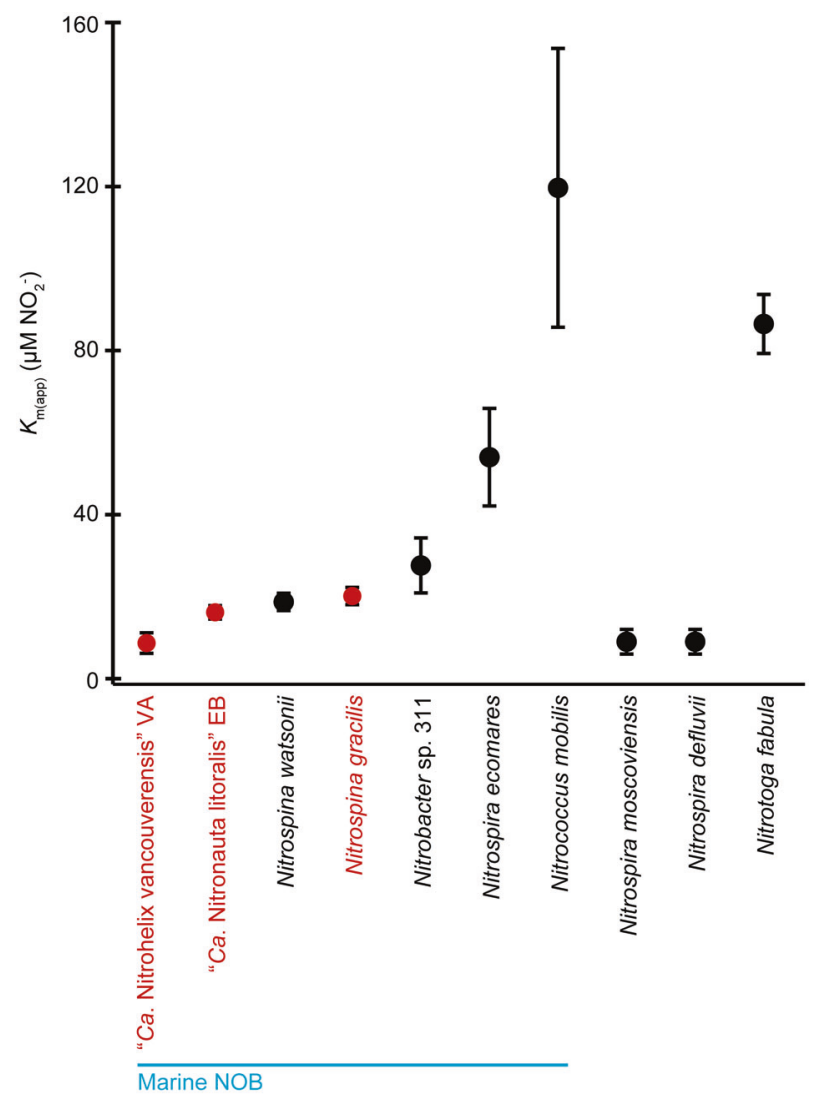

Fig. 4 Comparison of the whole-cell apparent half-saturation constants $\left(K_{\mathrm{m}(\mathrm{app})}\right)$ for nitrite between marine and non-marine NOB. The $K_{\mathrm{m}(\mathrm{app})}$ values measured in this study (highlighted in red) are the mean from all biological replicates ( $n=3$ for " $\mathrm{Ca}$. Nitrohelix vancouverensis" $\mathrm{VA} ; n=5$ for " $C a$. Nitronauta litoralis" $\mathrm{EB} ; n=8$ for $N$. gracilis). The other $K_{\mathrm{m}(\mathrm{app})}$ values were retrieved from previous studies [54, 55, 81].

and Escherichia coli under oligotrophic versus copiotrophic growth conditions $[59,60]$. Systematic assessments of the kinetic plasticity of NOB under different conditions are still pending, mainly because the production of sufficient biomass of NOB isolates has been a major obstacle for such studies.

\section{General genomic features of cultured Nitrospinae}

A pan-genomic analysis of the two novel cultured Nitrospinae strains and $N$. gracilis showed that these three organisms share a core genome of 1347 proteins, which have at least $50 \%$ amino acid sequence identity over $80 \%$ of the alignment (Fig. S6). The core genome included universally highly conserved bacterial genes, such as those coding for ribosomal proteins, translational elongation factors and the DNA replication machinery, as well as the genes for the core metabolism of chemolithoautotrophic NOB. Interestingly, among the shared conserved genes we also found highly conserved glutaredoxins, thioredoxin reductases, and peroxidases ( $>80 \%$ amino acid identity among the respective homologs). Like $N$. gracilis [25], 
"Ca. N. vancouverensis" and "Ca. N. litoralis" lack the canonical defense systems of aerobic organisms against oxidative stress, catalase and superoxide dismutase. While the aforementioned core genes could thus be essential for the detoxification of peroxides in all three organisms $[61,62]$, it remains a mystery how Nitrospinae deal with superoxide radicals [25]. Each of the strains encode a number of unique proteins (Fig. S6), many of which are phage related, corroborating a recently proposed hypothesis predicting extensive phage predation on Nitrospinae [21] (Supplemental Results and Discussion, Fig. S7). Yet, the majority of the variable genome content is still functionally uncharacterized. However, a few genes of the variable genome have known functions and might be important for niche adaptations. In the following sections, we address these genes as well as the shared core metabolism of the three analyzed Nitrospinae.

\section{Nitrite oxidation and respiration}

Among the highly conserved proteins are the three known subunits of a periplasmic NXR, NxrABC. Details of the predicted subunit composition and cofactors of the NXR of Nitrospinae, which is closely related to the NXR of Nitrospira, have been described elsewhere [3, 25, 63]. Briefly, all three Nitrospinae strains possess two genomic copies of the substrate-binding subunit NxrA, two or three (only "Ca. N. vancouverensis") copies of the electronchanneling subunit NxrB (Fig. S8), and several copies of putative NxrC subunits, which may transfer electrons from NXR to a downstream acceptor in the electron transport chain (Table S4). Homologs to all of the different putative $\mathrm{NxrC}$ subunits of $N$. gracilis [25] were also found in " $\mathrm{Ca}$. N. vancouverensis" and "Ca. N. litoralis" (Table S4), but it remains to be determined whether all of these proteins are functionally involved in nitrite oxidation.

The respiratory electron transport chain of NOB is short, as electrons derived from nitrite are directly transferred, via $a$ - or $c$-type cytochromes, to the terminal oxidase (complex IV) $[25,63,64]$. N. gracilis carries a $c b b_{3}$-type high affinity heme-copper cyt. $c$ oxidase (HCO) [25], whereas both " $\mathrm{Ca}$. $\mathrm{N}$. vancouverensis" and "Ca. N. litoralis" lack any canonical HCO. However, all three organisms encode highly conserved, putative " $b d$-like oxidases" [25]. These proteins, which also occur in all Nitrospira genomes, are phylogenetically related with but clearly distinct from the canonical cyt. $b d$-type quinol oxidases [63]. Interestingly, one variant of the $b d$-like oxidases from Nitrospira contains all conserved amino acid residues for heme and $\mathrm{Cu}$ binding in HCOs [65], indicating that this enzyme could be a novel cyt. $c$-oxidizing HCO [63]. The $b d$-like oxidases of $N$. gracilis, "Ca. N. vancouverensis", and " $C a$. N. litoralis" have most of these conserved residues; however, one of the three histidine ligands of the $\mathrm{Cu}_{\mathrm{B}}$ is replaced with a glutamine, and the histidine ligand of the high-spin heme is replaced with a phenylalanine. Thus, without the $c b b_{3}$-type oxidase found only in $N$. gracilis, it remains unclear how the final electron transport step from cyt. $c$ to $\mathrm{O}_{2}$ occurs in "Ca. N. vancouverensis" and "Ca. N. litoralis". Future biochemical and protein structural research may reveal whether the cyt. $b d$-like oxidases can catalyze this reaction despite their divergence from bona fide HCOs at two of the predicted cofactor-binding residues, and whether these proteins are capable of proton translocation for proton motive force generation. Corroborating evidence for a function of this enzyme in the context of electron transport stems from its highly conserved genetic synteny within Nitrospinae, Nitrospirae and anammox bacterial genomes. A conserved cluster within these organisms contains a cyt. $b d$-like oxidase with the aforementioned glutamine and phenylalanine residues, a diheme- and a triheme- cyt. $c$, and a membrane integral, alternative NxrC subunit (Tab. S4). This putative NxrC might be involved in the electron transfer from $\mathrm{NO}_{2}{ }^{-}$to the terminal oxidase $[25,63,66]$.

In addition to the putative cyt. $b d$-like oxidase discussed above, "Ca. N. litoralis" possesses a canonical cyt. $b d$-type (quinol) oxidase that is lacking in " $\mathrm{Ca}$. N. vancouverensis" and $N$. gracilis. Since quinol oxidases cannot accept electrons from the high-potential donor nitrite, we assume that this oxidase receives electrons from quinol during the degradation of intracellular glycogen or during hydrogen oxidation (see below). The cyt. $b d$-type oxidase may also be involved in oxidative stress defense, as homologous oxidases in other organisms can degrade $\mathrm{H}_{2} \mathrm{O}_{2}$ [67] and protect from dioxygen [68]. Taken together, the diverse repertoire of terminal oxidases may be a key feature of Nitrospinae that contributes to the ecological success of this lineage over a broad range of redox conditions in marine ecosystems.

\section{Carbon metabolism and alternative energy metabolisms}

Like $N$. gracilis and other Nitrospinae [6, 25], the novel strains encode all key genes of the reductive tricarboxylic acid (rTCA) cycle for $\mathrm{CO}_{2}$ fixation, including the hallmark enzymes ATP-citrate lyase (ACL), pyruvate:ferredoxin oxidoreductase (POR), and 2-oxogluterate:ferrodoxin oxidoreductase (OGOR) (Table S5). As in N. gracilis, all genes required for the oxidative (oTCA) cycle are also present. All three strains can form glycogen as storage compound, which is degraded via glycolysis and the oTCA cycle. Since $N$. gracilis lacks pyruvate kinase, the final step of glycolysis may be catalyzed by pyruvate phosphate dikinase (PPDK) in this organism. In contrast, strains VA and EB possess both pyruvate kinase and PPDK, indicating a strict regulatory separation between glycolysis and gluconeogenesis. 
Alternative energy metabolisms such as the oxidation of hydrogen, sulfide or organic carbon compounds have been demonstrated in NOB with representatives from the genera Nitrospira, Nitrococcus, Nitrolancea, and Nitrobacter [3, 26-28, 69]. Among the three Nitrospinae strains analyzed here, $N$. gracilis has the largest potential to exploit energy sources other than nitrite: its genome harbors a bidirectional type $3 b[\mathrm{NiFe}]$ hydrogenase, which could enable aerobic hydrogen utilization, and a sulfite:cyt. $c$ oxidoreductase [25]. In addition, $N$. gracilis contains the genes $\operatorname{prp} B C D$ for 2-methylisocitrate lyase, 2-methylcitrate synthase, and 2-methylcitrate dehydratase, and might thus be able to catabolically degrade propionate via the 2methylcitrate pathway (Fig. 5). Of these potential alternative energy metabolisms, "Ca. N. litoralis" shares only the type
$3 \mathrm{~b}$ hydrogenase, whereas " $\mathrm{Ca}$. N. vancouverensis" seems to be an obligate nitrite oxidizer. No genes for the uptake and utilization of urea and cyanate as organic $\mathrm{N}$ sources were found in the genomes of the new strains. These genes show a patchy distribution among Nitrospinae [6, 7, 20, 21, 25], suggesting further niche differentiation of these organisms based on the capacity to use organic compounds as sources of reduced $\mathrm{N}$ for assimilation.

\section{Adaptations to saline environments}

The intracellular accumulation of ions or the production of organic osmolytes are two main strategies of microorganisms to cope with the osmotic stress in highly saline, marine environments. Interestingly, the three Nitrospinae strains

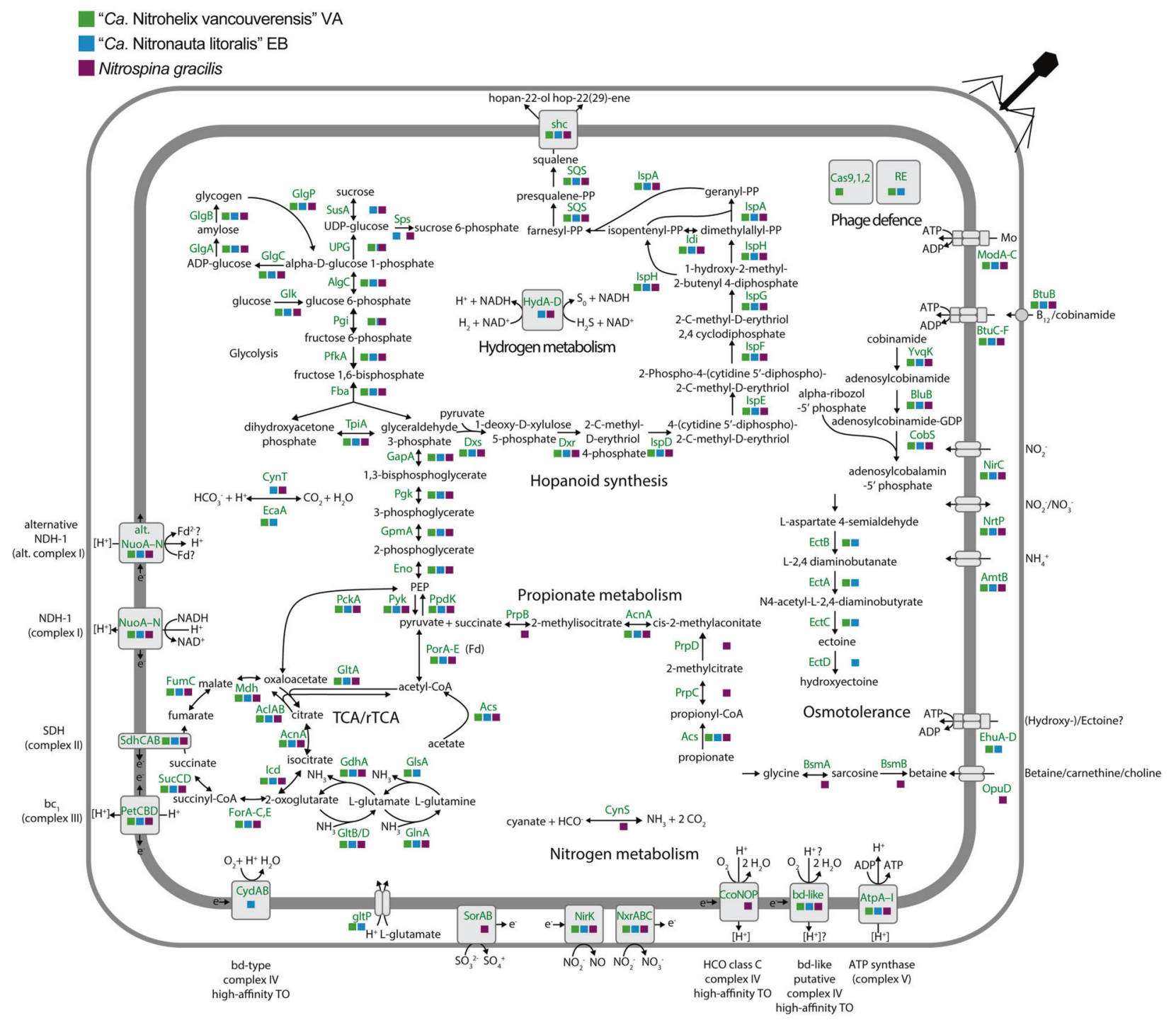

Fig. 5 Cell cartoon based on the annotation of " $\mathrm{Ca}$. Nitrohelix vancouverensis" VA, “Ca. Nitronauta litoralis" EB and $N$. gracilis 3/211. The colored squares indicate the presence or absence of the respective genes, " $\mathrm{Ca}$. Nitrohelix vancouverensis" VA is shown in green,
"Ca. Nitronauta litoralis" EB in blue, and $N$. gracilis $3 / 211$ in purple. The gene annotations are detailed in Table S5. Fd ferredoxin, RE restriction enzymes, TO terminal oxidase. 
seem to utilize different osmotic stress defense mechanisms. $N$. gracilis has the genetic potential to produce glycine betaine, an organic osmolyte that is ubiquitously found in bacteria (Fig. 5) [70]. It also encodes for OpuD, a betaine/ carnitine/choline transporter, whereas the genes for glycine betaine synthesis and import are missing in " $\mathrm{Ca}$. N. vancouverensis" and " $\mathrm{Ca}$. N. litoralis". These two strains harbor the canonical genes ect $A B C$ for ectoine biosynthesis (Fig. 5), another widely distributed osmolyte in bacteria [70]. " $\mathrm{Ca}$. N. litoralis" additionally encodes the ectoine hydroxylase EctD and is thus able to form hydroxyectoine. Directly downstream of the (hydroxy-)ectoine synthesis cassette, the two strains further encode an $\mathrm{ABC}$ transporter that has similarity to ectoine or amino acid transporters from other organisms and may be utilized for (hydroxy-)ectoine import across the cytoplasmic membrane. Since genes for the synthesis and transport of (hydroxy-)ectoine were also found in "Ca. Nitromaritima" (Nitrospinae clade 1) [6], we assume that usage of (hydroxy-)ectoine is wide-spread among the Nitrospinae. $N$. gracilis and " $\mathrm{Ca}$. N. litoralis" may also be able to synthesize sucrose as an additional compatible solute (Fig. 5).

Moreover, "Ca. N. vancouverensis" and "Ca. N. litoralis" genomes harbor the gene glsA coding for a glutaminase (Fig. 5), which allows them to deaminate glutamine to glutamate while releasing ammonia. The strains further possess the gltP gene coding for a glutamate/ $\mathrm{H}^{+}$symporter. Both $g l s A$ and gltP seem to be lacking in the $N$. gracilis genome. Since glutamate can play a role in osmoregulation [70], the ability to regulate the intracellular glutamate level via transport or the degradation of glutamine may be one of various adaptations by " $\mathrm{Ca}$. N. vancouverensis" and " $\mathrm{Ca}$. N. litoralis" to rapidly respond to stress caused by fluctuating salinities.

All three Nitrospinae strains have the genomic capacity to synthesize the hopanoids hopan-(22)-ol and hop-22(29)ene (Fig. 5). Hopanoids are pentacyclic, bacterial lipids that integrate into bacterial membranes, much like cholesterol in eukaryotes [71]. They help regulate membrane fluidity and may be important in highly saline environments [70, 72]. Knock-out studies have shown that cells lacking the ability to make hopanoids are more sensitive to various stresses, such as temperature, $\mathrm{pH}$ and osmolarity [72]. Interestingly, a metagenomic study of hopanoid-producing bacteria in the Red Sea revealed Nitrospinae to be among the main organisms harboring squalene hopene cyclase, the key gene for hopanoid production [73]. Other marine NOB (members of Nitrospira, Nitrobacter and Nitrococcus mobilis), and even non-marine Nitrospira and Nitrobacter, also have the squalene hopene cyclase and therefore the genomic potential to produce hopanoids. Insight into the chemical structure of the hopanoids produced by NOB could help to gain insight into early NOB evolution as hopanoids are important lipid biomarkers and commonly used to deduce ancient microbial activity from sediment fossil records [73].

\section{Vitamin B12 auxotrophy}

The three Nitrospinae strains lack multiple genes involved in vitamin B12 (cobalamin) synthesis and seem to be auxotrophic for this vitamin, as previously suggested for $N$. gracilis [74]. To acquire vitamin B12 from the environment, all strains encode the vitamin $\mathrm{B} 12 \mathrm{ABC}$ transporter $b t u C D F$ and the outer membrane permease btuB [75, 74]. Alternatively, this transporter may also import cobinamide that may then be converted to vitamin B12 via a salvage pathway that uses the genes $y v q K, b l u B$, and $c o b S$, each encoded in all three Nitrospinae genomes [76]. Hence, the availability of externally supplied vitamin B12 or cobinamide is likely of crucial importance for Nitrospinae in situ and also in lab cultures. The incomplete cobalamin pathway in the already available $N$. gracilis genome led us to amend the cultivation medium with vitamin B12. Indeed, the addition of vitamin B12, either alone or together with other vitamins, has allowed us to cultivate $N$. gracilis in a more defined medium that is based on Red Sea salt. Previously, the standard medium for this organism had to be prepared from natural seawater [25]. Furthermore, the addition of vitamin B12 was likely an essential prerequisite for our successful enrichment of novel Nitrospinae after cell sorting. The co-cultured alphaproteobacteria may also provide additional vitamin $\mathrm{B} 12$ as they both have the genomic repertoire for its synthesis. In the environment, vitamin B12 could be supplied by different heterotrophic or autotrophic microorganisms, including ammonia-oxidizing thaumarchaeota, which have been shown to produce vitamin B12 [77-79] and often co-occur with Nitrospinae [10, 21, 80].

\section{Conclusions}

Nitrospinae are important players in marine nitrogen and carbon cycling, but difficulties to cultivate these bacteria have been a major obstacle for their characterization. In this study, the usually very time-consuming enrichment and purification procedure of marine NOB was accelerated by combining cell sorting with genome-informed adjustments to the cultivation medium. By employing this method, we were able to obtain two new, highly enriched Nitrospinae strains, which represent two novel genera in the Nitrospinae and double the number of available cultures from this phylum. A comparison of their completely sequenced genomes and that of $N$. gracilis revealed numerous shared metabolic features, as well as several non-shared, putative adaptations in these distantly related Nitrospinae. With the new cultures at hand, it will now be possible to 
systematically test such genome-based hypotheses and to elucidate the ecological roles played by members of the Nitrospinae within and beyond the nitrogen cycle.

\section{Taxonomic consideration of "Candidatus Nitrohelix vancouverensis" gen. nov. sp. nov}

Ni.tro.he'lix L. n. nitrum: nitrate, L. n. helix: a coil, spiral; N.L. fem. n. Nitrohelix nitrate-forming spiral. van.cou.ver. en'sis L. fem. adj. vancouverensis of Vancouver.

A nitrate-forming helical bacterium obtained from Vancouver, Canada. Phylogenetically affiliated with the family Nitrospinaceae, phylum Nitrospinae. Cells are gramnegative helically shaped rods with 1-3 turns and a length of $\sim 3 \mu \mathrm{m}$. The genome consists of a single chromosome of $3,309,797 \mathrm{bp}$. The DNA G $+\mathrm{C}$ content is $51 \mathrm{~mol} \%$.

Strain "Candidatus Nitrohelix vancouverensis VA" was cultivated from coastal surface sediment from Vancouver, Canada. Marine aerobic chemolithoautotroph that oxidizes nitrite to nitrate. $K_{\mathrm{m}(\mathrm{app})}$ is $8.7 \pm 2.5 \mu \mathrm{M} \mathrm{NO}_{2}{ }^{-}$. The strain was routinely cultured with $0.5 \mathrm{mM}$ nitrite at $28{ }^{\circ} \mathrm{C}$ in liquid marine mineral medium. Could not be grown on solid medium. Auxotrophic for vitamin B12 according to genome analysis.

\section{Taxonomic consideration of "Candidatus Nitronauta litoralis" gen. nov. sp. nov}

Ni.tro.nau'ta L. n. nitrum: nitrate, L. n. nauta: seaman; N.L. masc. n. Nitronauta nitrate-forming seaman. li.to.ra'lis L. masc. adj. litoralis coastal.

A nitrate-forming marine bacterium found in a coastal habitat. Phylogenetically affiliated with the family Nitrospinaceae, phylum Nitrospinae. Cells are gram-negative short rods with a length of $\sim 1.5 \mu \mathrm{m}$. The genome consists of a single chromosome of 3,921,641 bp. The DNA G+C content is $47 \mathrm{~mol} \%$.

Strain "Candidatus Nitronauta litoralis EB" was cultivated from coastal surface sediment from Elba, Italy. Marine aerobic chemolithoautotroph that oxidizes nitrite to nitrate. $K_{\mathrm{m}(\mathrm{app})}$ is $16.2 \pm 1.6 \mu \mathrm{M} \mathrm{NO}_{2}{ }^{-}$. The strain was routinely cultured with $1-5 \mathrm{mM}$ nitrite at $28{ }^{\circ} \mathrm{C}$ in liquid marine mineral medium. Could not be grown on solid medium. Auxotrophic for vitamin B12 according to genome analysis.

Acknowledgements We would like to thank Julia Polzin and Jillian Petersen for providing sediment samples from Elba. We are also grateful for the help from Daniela Gruber at the Core Facility of Cell Imaging and Ultrastructure Research at the University of Vienna, who supported sample preparation and visualization of electron microscopy samples. We would further like to thank Karin Kohlweiss for performing FACS and the BOKU Core Facility for Biomolecular and Cellular Analysis and EQ-BOKU VIBT GmbH for access to equipment. We greatly appreciate Mads Albertsen and Soeren M. Karst for the Nanopore sequencing conducted during the course "Hands-on
Metagenomics using Oxford Nanopore DNA Sequencing". We also thank Marcel Kuypers, Katharina Kitzinger, Hannah Marchant, and Bela Hausmann for valuable discussions and Bernhard Schink for advice on naming the new organisms. This study was supported by the Austrian Science fund (FWF) project Microbial Nitrogen Cycling From Single Cells to Ecosystems (W1257). AJM was partially supported by a Fellowship from the Natural Science and Engineering Council of Canada Postgraduate Scholarship-Doctoral (NSERC PGSD). MYJ was supported by an ERC Advanced Grant project to MW (Nitricare; 294343).

\section{Compliance with ethical standards}

Conflict of interest RHK owns part of DNASense ApS. The remaining authors declare no conflict of interests.

Publisher's note Springer Nature remains neutral with regard to jurisdictional claims in published maps and institutional affiliations.

Open Access This article is licensed under a Creative Commons Attribution 4.0 International License, which permits use, sharing, adaptation, distribution and reproduction in any medium or format, as long as you give appropriate credit to the original author(s) and the source, provide a link to the Creative Commons license, and indicate if changes were made. The images or other third party material in this article are included in the article's Creative Commons license, unless indicated otherwise in a credit line to the material. If material is not included in the article's Creative Commons license and your intended use is not permitted by statutory regulation or exceeds the permitted use, you will need to obtain permission directly from the copyright holder. To view a copy of this license, visit http://creativecommons. org/licenses/by/4.0/.

\section{References}

1. Diaz RJ, Rosenberg R. Spreading Dead Zones and Consequences for Marine Ecosystems. Science. 2008;32:926-9.

2. Ward BB. Nitrification in marine systems. In: Capone DG, Bronk DA, Mulholland MR, Carpenter EJ, editors. Nitrogen in the Marine Environment. 2nd edn. San Diego: Elsevier Academic Press; 2008. p. 199-261.

3. Daims H, Lücker S, Wagner M. A new perspective on microbes formerly known as nitrite-oxidizing bacteria. Trends Microbiol. 2016;24:699-712.

4. Parks DH, Chuvochina M, Waite DW, Rinke C, Skarshewski A, Chaumeil PA, et al. A standardized bacterial taxonomy based on genome phylogeny substantially revises the tree of life. Nat Biotechnol. 2018;36:996.

5. Füssel J, Lam P, Lavik G, Jensen MM, Holtappels M, Günter M, et al. Nitrite oxidation in the Namibian oxygen minimum zone. ISME J. 2012;6:1200-9.

6. Ngugi DK, Blom J, Stepanauskas R, Stingl U. Diversification and niche adaptations of - Nitrospina like bacteria in the polyextreme interfaces of Red Sea brines. ISME J. 2015;10:1-17.

7. Sun X, Kop LFM, Lau MCY, Frank J, Jayakumar A, Lücker S, et al. Uncultured Nitrospina-like species are major nitrite oxidizing bacteria in oxygen minimum zones. ISME J. 2019;13:2391-402.

8. Garcia-Robledo E, Padilla CC, Aldunate M, Stewart FJ, Ulloa O, Paulmier A, et al. Cryptic oxygen cycling in anoxic marine zones. Proc Natl Acad Sci USA. 2017;114:8319-24.

9. Levipan HA, Molina V, Fernandez C. Nitrospina-like bacteria are the main drivers of nitrite oxidation in the seasonal upwelling area of the Eastern South Pacific (Central Chile $\sim 36^{\circ} \mathrm{S}$ ). Environ Microbiol Rep. 2014;6:565-73. 
10. Mincer TJ, Church MJ, Taylor LT, Preston C, Karl DM, DeLong EF. Quantitative distribution of presumptive archaeal and bacterial nitrifiers in Monterey Bay and the North Pacific Subtropical Gyre. Environ Microbiol. 2007;9:1162-75.

11. Hawley AK, Brewer HM, Norbeck AD, Pasă-Tolić L, Hallam SJ. Metaproteomics reveals differential modes of metabolic coupling among ubiquitous oxygen minimum zone microbes. Proc Natl Acad Sci USA. 2014;111:11395-11400.

12. Saito MA, McIlvin MR, Moran DM, Santoro AE, Dupont CL, Rafter PA, et al. Abundant nitrite-oxidizing metalloenzymes in the mesopelagic zone of the tropical Pacific Ocean. Nat Geosci. 2020;13:355-62.

13. Nunoura T, Takaki Y, Hirai M, Shimamura S, Makabe A, Koide $\mathrm{O}$, et al. Hadal biosphere: insight into the microbial ecosystem in the deepest ocean on Earth. Proc Natl Acad Sci USA. 2015;112: E1230-E1236.

14. Rani S, Koh H, Rhee S, Fujitani H. Detection and Diversity of the Nitrite Oxidoreductase Alpha Subunit (nxrA) Gene of Nitrospina in Marine Sediments. Micro Ecol. 2017;37:111-22.

15. Santoro AE, Casciotti KL, Francis CA. Activity, abundance and diversity of nitrifying archaea and bacteria in the central California Current. Environ Microbiol. 2010;12:1989-2006.

16. Damashek J, Tolar BB, Liu Q, Okotie-Oyekan AO, Wallsgrove NJ, Popp BN, et al. Microbial oxidation of nitrogen supplied as selected organic nitrogen compounds in the South Atlantic Bight. Limnol Oceanogr. 2019;64:982-95.

17. Jorgensen SL, Hannisdal B, Lanzén A, Baumberger T, Flesland K, Fonseca R, et al. Correlating microbial community profiles with geochemical data in highly stratified sediments from the Arctic MidOcean Ridge. Proc Natl Acad Sci USA. 2012;109:E2846-E2855.

18. Bristow LA, Dalsgaard T, Tiano L, Mills DB, Bertagnolli AD, Wright $\mathrm{JJ}$, et al. Ammonium and nitrite oxidation at nanomolar oxygen concentrations in oxygen minimum zone waters. Proc Natl Acad Sci USA. 2016;113:10601-6.

19. Lipschultz F, Wofsy SC, Ward BB, Codispoti LA, Friedrich G, Elkins JW. Bacterial transformations of inorganic nitrogen in the oxygen-deficient waters of the Eastern Tropical South Pacific Ocean. Deep Sea Res Part A Oceanogr Res Pap. 1990;37:1513-41.

20. Pachiadaki MG, Sintes E, Bergauer K, Brown JM, Record NR, Swan BK, et al. Major role of nitrite-oxidizing bacteria in dark ocean carbon fixation. Science. 2017;358:1046-51.

21. Kitzinger K, Marchant HK, Bristow LA, Herbold CW, Padilla CC, Kidane AT, et al. Single cell analyses reveal contrasting life strategies of the two main nitrifiers in the ocean. Nat Commun. 2020;11:767.

22. Zhang Y, Qin W, Hou L, Zakem EJ, Wan X, Zhao Z, et al. Nitrifier adaptation to low energy flux controls inventory of reduced nitrogen in the dark ocean. Proc Natl Acad Sci USA. 2020;117:4823-30.

23. Watson SW, Waterbury JB. Characteristics of Two Marine Nitrite Oxidizing Bacteria, Nitrospina gracilis nov. ten. nov. sp. and Nitrococcus mobilis nov. ten. nov. sp.*. Arch Mikrobiol. 1971;77:203-30.

24. Spieck E, Keuter S, Wenzel T, Bock E, Ludwig W. Characterization of a new marine nitrite oxidizing bacterium, Nitrospina watsonii sp. nov., a member of the newly proposed phylum " Nitrospinae". Syst Appl Microbiol. 2014;37:170-6.

25. Lücker S, Nowka B, Rattei T, Spieck E, Daims H. The genome of Nitrospina gracilis illuminates the metabolism and evolution of the major marine nitrite oxidizer. Front Microbiol Microbiol. 2013;4:1-19.

26. Koch H, Galushko A, Albertsen M, Schintlmeister A, GruberDoringer C, Lücker S, et al. Growth of nitrite-oxidizing bacteria by aerobic hydrogen oxidation. Science. 2014;345:1052-4.

27. Koch H, Lücker S, Albertsen M, Kitzinger K, Herbold C, Spieck E. Expanded metabolic versatility of ubiquitous nitrite-oxidizing bacteria from the genus Nitrospira. Proc Natl Acad Sci USA. 2015;112:11371-6.
28. Sorokin DY, Vejmelkova D, Lücker S, Streshinskaya GM, Rijpstra WIC, Sinninghe Damsté JS, et al. Nitrolancea hollandica gen. nov., sp. nov., a chemolithoautotrophic nitrite-oxidizing bacterium isolated from a bioreactor belonging to the phylum Chloroflexi. Int J Syst Evol Microbiol. 2014;64:1859-65.

29. Lebedeva EV, Alawi M, Jozsa PG, Daims H, Spieck E. Physiological and phylogenetic characterization of a novel lithoautotrophic nitrite-oxidizing bacterium, 'Candidatus Nitrospira bockiana'. Int J Syst Evol Microbiol. 2008;58:242-50.

30. Lee KS, Palatinszky M, Pereira FC, Nguyen J, Fernandez VI, Mueller AJ, et al. An automated Raman-based platform for the sorting of live cells by functional properties. Nat Microbiol. 2019;4:1035-48.

31. Kim JG, Park SJ, Sinninghe Damsté JS, Schouten S, Rijpstra WIC, Jung MY, et al. Hydrogen peroxide detoxification is a key mechanism for growth of ammonia-oxidizing archaea. Proc Natl Acad Sci USA. 2016;113:7888-93.

32. Miranda KM, Espey MG, Wink DA. A Rapid, Simple Spectrophotometric Method for Simultaneous Detection of Nitrate and Nitrite. Nitric Oxide. Biol Chem. 2001;5:62-71.

33. Vallenet D, Calteau A, Dubois M, Amours P, Bazin A, Beuvin M, et al. MicroScope: an integrated platform for the annotation and exploration of microbial gene functions through genomic, pangenomic and metabolic comparative analysis. Nucleic Acids Res. 2020;48:D579-D589.

34. Parks DH, Imelfort M, Skennerton CT, Hugenholtz P, Tyson GW. CheckM: Assessing the quality of microbial genomes recovered from isolates, single cells, and metagenomes. Genome Res. 2015;25:1043-55.

35. Nguyen LT, Schmidt HA, Von Haeseler A, Minh BQ. IQ-TREE: a fast and effective stochastic algorithm for estimating maximumlikelihood phylogenies. Mol Biol Evol. 2015;32:268-74.

36. Kalyaanamoorthy S, Minh BQ, Wong TKF, Von Haeseler A, Jermiin LS. ModelFinder: fast model selection for accurate phylogenetic estimates. Nat Methods. 2017;14:587-9.

37. Hoang DT, Chernomor O, von Haeseler A, Minh BQ, Vinh LS. UFBoot2: improving the Ultrafast Bootstrap Approximation. Molecular biology and evolution. Mol Biol Evol. 2018;35:518-22.

38. Konstantinidis KT, Tiedje JM. Towards a genome-based taxonomy for prokaryotes. J Bacteriol. 2005;187:6258-64.

39. Varghese NJ, Mukherjee S, Ivanova N, Konstantinidis $\mathrm{T}$, Mavrommatis K, Kyrpides NC, et al. Microbial species delineation using whole genome sequences. Nucleic Acids Res. 2015; 43:6761-71.

40. Daebeler A, Herbold CW, Vierheilig J, Sedlacek CJ, Pjevac P, Albertsen M, et al. Cultivation and genomic analysis of 'Candidatus Nitrosocaldus islandicus,' an obligately thermophilic, ammonia-oxidizing thaumarchaeon from a hot spring biofilm in Graendalur valley, Iceland. Front Microbiol. 2018;9:1-16.

41. R Core Team. R: a language and environment for statistical computing. Vienna, Austria: R Foundation for Statistical Computing; 2019.

42. Kits KD, Sedlacek CJ, Lebedeva EV, Han P, Bulaev A, Pjevac P, et al. Kinetic analysis of a complete nitrifier reveals an oligotrophic lifestyle. Nature. 2017;549:269-72.

43. Fujitani H, Kumagai A, Ushiki N, Momiuchi K. Selective isolation of ammonia-oxidizing bacteria from autotrophic nitrifying granules by applying cell-sorting and sub-culturing of microcolonies. Front Microbiol. 2015;6:1159.

44. Uchiyama T, Watanabe K. Substrate-induced gene expression (SIGEX) screening of metagenome libraries. Nat Protoc. 2008; $3: 1202-12$

45. Ostafe R, Prodanovic R, Commandeur U, Fischer R. Flow cytometry-based ultra-high-throughput screening assay for cellulase activity. Anal Biochem. 2013;435:93-98.

46. Pereira H, Barreira L, Mozes A, Florindo C, Polo C, Duarte CV, et al. Microplate-based high throughput screening procedure for 
the isolation of lipid-rich marine microalgae. Biotechnol Biofuels. 2011;4:61.

47. Rüger H-J, Höfle MG. Marine Star-Shaped-Aggregate-Forming Bacteria: Agrobacterium atlanticum sp. nov.; Agrobacterium meteori sp. nov.; Agrobacterium ferrugineum sp. nov., nom. rev.; Agrobacterium gelatinovorum sp. nov., nom. rev.; and Agrobacterium stellulatum sp. nov., nom. Int J Syst Bacteriol. 1992;42:133-43.

48. Lee K, Choo Y, Giovannoni SJ, Cho J. Maritimibacter alkaliphilus gen. nov., sp. nov., a genome-sequenced marine bacterium of the Roseobacter clade in the order Rhodobacterales. Int J Syst Evol Microbiol. 2007;57:1653-8.

49. Morris JJ, Johnson ZI, Szul MJ, Keller M, Zinser ER. Dependence of the cyanobacterium Prochlorococcus on hydrogen peroxide scavenging microbes for growth at the ocean's surface. PLoS ONE. 2011;6:e16805.

50. Bayer B, Pelikan C, Bittner MJ, Reinthaler T, Herndl GJ, Offre P. Proteomic Response of Three Marine Ammonia-Oxidizing Archaea to Hydrogen Peroxide and Their Metabolic Interactions with a Heterotrophic Alphaproteobacterium. mSystems 2019;4:1-15.

51. Bayer B, Hansman RL, Bittner MJ, Noriega-ortega BE, Niggemann J, Dittmar T, et al. Ammonia-oxidizing archaea release a suite of organic compounds potentially fueling prokaryotic heterotrophy in the ocean. Environ Microbiol. 2019;21:4062-75.

52. Rodriguez-r LM, Konstantinidis KT, Sequence-discrete MF. Bypassing Cultivation To Identify Bacterial Species. Microbe. 2014;9:111-8.

53. Watson SW, Bock E, Valois FW, Waterbury JB, Schlosser U. Nitrospira marina gen. nov. sp. nov.: a chemolithotrophic nitriteoxidizing bacterium. Arch Microbiol. 1986;144:1-7.

54. Nowka B, Daims H, Spieck E. Comparison of oxidation kinetics of nitrite-oxidizing bacteria: Nitrite availability as a key factor in niche differentiation. Appl Environ Microbiol. 2015;81:745-53.

55. Jacob J, Nowka B, Merten V, Sanders T, Spieck E, Dähnke K. Oxidation kinetics and inverse isotope effect of marine nitriteoxidizing isolates. Aquat Micro Ecol. 2017;80:289-300.

56. Ushiki N, Jinno M, Fujitani H, Suenaga T, Terada A, Tsuneda S. Nitrite oxidation kinetics of two Nitrospira strains: the quest for competition and ecological niche differentiation. J Biosci Bioeng. 2017;123:581-9.

57. Sun X, Ji Q, Jayakumar A, Ward BB. Dependence of nitrite oxidation on nitrite and oxygen in low-oxygen seawater. Geophys Res Lett. 2017;44:7883-91.

58. Jones R, Morita R. Low-temperature growth and whole-cell kinetics of a marine ammonium oxidizer. Mar Ecol Prog Ser. 1985;21:239-43.

59. Kovárová-Kovar K, Egli T. Growth kinetics of suspended microbial cells: from single-substrate-controlled growth to mixedsubstrate kinetics. Microbiol Mol Biol Rev. 1998;62:646-66.

60. Martens-Habbena W, Stahl DA. Nitrogen metabolism and kinetics of ammonia-oxidizing archaea. In: Klotz MG, Stein LY, editors. Research on Nitrification and Related Processes, Part B. 1st edn. San Diego: Elsevier Academic Press; 2011. p. 465-87.

61. Serata M, Iino T, Yasuda E, Sako T. Roles of thioredoxin and thioredoxin reductase in the resistance to oxidative stress in Lactobacillus casei. Microbiology 2012;158:953-62.

62. Song JJ, Rhee JG, Suntharalingam M, Walsh SA, Spitz DR, Lee YJ. Role of glutaredoxin in metabolic oxidative stress: Glutaredoxin as a sensor of oxidative stress mediated by $\mathrm{H} 2 \mathrm{O} 2$. J Biol Chem. 2002;277:46566-75.

63. Lücker S, Wagner M, Maixner F, Pelletier E, Koch H, Vacherie B, et al. A Nitrospira metagenome illuminates the physiology and evolution of globally important nitrite-oxidizing bacteria. Proc Natl Acad Sci USA 2010;107:13479-84.
64. Bock E, Wagner M. Oxidation of Inorganic Nitrogen Compounds as an Energy Source. In: Dworkin M, Falkow S, Rosenberg E, Schleifer K-H, Stackebrandt E, editors. The Prokaryotes: Volume 2: Ecophysiology and Biochemistry. 3rd edn. New York: Springer New York; 2006. p. 457-95.

65. Pereira MM, Santana M, Teixeira M. A novel scenario for the evolution of haem-copper oxygen reductases. Biochim Biophys Acta Bioenerg. 2001;1505:185-208.

66. Mundinger AB, Lawson CE, Jetten MSM, Koch H, Lücker S. Cultivation and Transcriptional Analysis of a Canonical Nitrospira Under Stable Growth Conditions. Front Microbiol. 2019; 10:1325.

67. Borisov VB, Forte E, Davletshin A, Mastronicola D, Sarti P, Giuffrè A. Cytochrome bd oxidase from Escherichia coli displays high catalase activity: An additional defense against oxidative stress. FEBS Lett. 2013;587:2214-8.

68. Das A, Silaghi-Dumitrescu R, Ljungdahl LG, Kurtz DMOxidase. Oxidative Stress, and Dioxygen Tolerance of the Strictly Anaerobic Bacterium. J Bacteriol. 2005;187:2020-9.

69. Steinmüller W, Bock E. Growth of Nitrobacter in the Presence of Organic Matter. Arch Microbiol. 1976;108:299-304.

70. Banciu H, Sorokin DY. Adaptation in Haloalkaliphiles and Natronophilic Bacteria. In: Seckbach J, Oren A, Stan-Lotter H, editors. Polyextremophiles. Dordrecht: Springer; 2013. p. 249-67.

71. Sáenz JP, Grosser D, Bradley AS, Lagny TJ, Lavrynenko O, Broda M, et al. Hopanoids as functional analogues of cholesterol in bacterial membranes. Proc Natl Acad Sci USA. 2015;112: 11971-6.

72. Belin BJ, Busset N, Giraud E, Molinaro A, Silipo A, Newman DiK. Hopanoid lipids: from membranes to plant-bacteria interactions. Nat Rev Microbiol. 2018;16:304-15.

73. Kharbush JJ, Thompson LR, Haroon MF, Knight R, Aluwihare LI. Hopanoid-producing bacteria in the Red Sea include the major marine nitrite oxidizers. FEMS Microbiol Ecol. 2018;94:1-9.

74. Tian R-M, Sun J, Cai L, Zhang W-P, Zhou G-W, Qiu J-W, et al. The deep-sea glass sponge Lophophysema eversa harbours potential symbionts responsible for the nutrient conversions of carbon, nitrogen and sulfur. Environ Microbiol. 2016;18:2481-94.

75. Klein JS, Lewinson O. Bacterial ATP-driven transporters of transition metals: physiological roles, mechanisms of action, and roles in bacterial virulence. Metallomics. 2011;3:1098-108.

76. Fang H, Kang J, Zhang D. Microbial production of vitamin B12: a review and future perspectives. Micro Cell Fact. 2017;16:1-14.

77. Doxey AC, Kurtz DA, Lynch MDJ, Sauder LA, Neufeld JD. Aquatic metagenomes implicate Thaumarchaeota in global cobalamin production. ISME J. 2015;9:461-71.

78. Heal KR, Qin W, Ribalet F, Bertagnolli AD, Coyote-maestas W, Hmelo LR. Two distinct pools of B12 analogs reveal community interdependencies in the ocean. Proc Natl Acad Sci USA. 2016; 114:364-9.

79. Heal KR, Qin W, Amin SA, Devol AH, Moffett JW, Armbrust $\mathrm{EV}$, et al. Accumulation of $\mathrm{NO}_{2}$-cobalamin in nutrient-stressed ammonia-oxidizing archaea and in the oxygen de fi cient zone of the eastern tropical North Pacific. Environ Microbiol Rep. 2018; 10:453-7.

80. Park BJ, Park SJ, Yoon DN, Schouten S, Damsté JSS, Rhee SK. Cultivation of autotrophic ammonia-oxidizing archaea from marine sediments in coculture with sulfur-oxidizing bacteria. Appl Environ Microbiol. 2010;76:7575-87.

81. Kitzinger K, Koch H, Lücker S, Sedlacek CJ, Herbold C, Schwarz $\mathrm{J}$, et al. Characterization of the first "Candidatus Nitrotoga" isolate reveals metabolic versatility and separate evolution of widespread nitrite-oxidizing bacteria. MBio 2018;9:1-16. 